\title{
Chapter 35 \\ Using Agent-Based Simulation to Understand the Role of Values in Policy-Making
}

\author{
Antoni Perello-Moragues and Pablo Noriega
}

\begin{abstract}
We propose to explore the role of values in policy-making and the use of ABS for elucidating this role. In this paper we outline a conceptual framework for value-driven modelling of public policies and illustrate it with an agent-based simulation of irrigation practices.
\end{abstract}

Keywords Agent-based simulation · Policy-making · Policy values

\subsection{Introduction}

It is generally acknowledged that policy-making is about achieving a better state of the world, and, consequently, at design time, it implies that policy-makers make choices based on values [14, 45]. However, the actual effects of those choices are difficult to assess, since the real world is complex [25]. Moreover, policymakers need to address trade-offs between the conflicting interests of the several stakeholders. We postulate that one way to deal with this complexity is to elucidate how values are involved in those decision-making processes.

For this purpose, we are following a threefold strategy: (i) first, we develop a theoretical framework that articulates the interplay between the activities involved in the policy-making cycle and the value-based choices of the main stakeholders; (ii) second, we propose to use agent-based simulation (ABS) to visualise the relationships between policy goals and instruments, on one side, and the behaviour

\author{
A. Perello-Moragues $(\square)$ \\ IIIA-CSIC, Barcelona, Spain \\ Aqualia, Madrid, Spain \\ Universitat Autònoma de Barcelona, Bellaterra, Spain \\ e-mail: tperello@iiia.csic.es; antonio.perello@fcc.es \\ P. Noriega $(\square)$ \\ IIIA-CSIC, Barcelona, Spain \\ e-mail: pablo@iiia.csic.es
}


of those agents for whom the policy is intended, on the other; (iii) third, we focus our attention on a specific policy domain - the use of water in agriculture-in order to draw inspiration from realistic examples, have access to empirical data and expert advice, and develop guidelines for a wider application of our proposal.

In this paper we show how ABS may be used to explore the role of values in the agenda-setting stage of the policy-making cycle. More specifically, we outline our conceptual framework in Sect. 35.3 and its background in Sect. 35.2. In Sect. 35.4 we discuss a model that illustrates the gist of our proposal. The model is based on actual agricultural data and practices, but we present a simplified version to illustrate the interplay between two policies-based on different values-for regulating irrigation practices in a community of farmers whose individual decisions are guided by different value sets. After the discussion of this example, we identify some key challenges and sketch our future research plan.

\subsection{Background and State of the Art}

\subsubsection{Values and Behaviour}

Values are at the core of decision-making, motivations, preferences, and attitudesalthough they are not the same concepts [18, 34]. Schwartz et al. [41] defined values as "concepts or beliefs, about desirable end states or behaviours, that transcend specific situations, guide selection or evaluation of behaviour and events, and are ordered by relative importance".

Rohan [37] pointed out the definitional multifariousness of the "value" construct. Nevertheless, there is a consensus that values play an active role in the intentional human behaviour and decision-making — regardless of whether the reasoning about them is conscious or not [34].

This leads to postulate that individuals hold different rationalities [42]: decisions are made because they serve the values of an actor as the actor sees them. Besides values, they use other constructs, such as mental models, that are used to understand and interact with the environment [26], that provide explanations and inferences about diverse phenomena [10], and often are incomplete and biased [6, 17, 26]. We assume, therefore, that agents hold mind-frames, containing values and other constructs that support decision-making. They are often collectively shared, like other socially developed constructs $[17,18,28]$.

There is no consensus on the categories of values. We identify, as fundamental categories, (i) individual values and (ii) social values (see [38]). Individual values refer to those values towards satisfying needs and self-esteem [39]. In contrast, social values are values of society at large, concerning public interest or contribution to well-being, that emerge from the society or social group [28] and that would include also desirable properties with regard to governance [49]. However, this emergence is not trivial. When referring to social values of a single agent, one 
may assume that such emergence is based in the agent's consideration of the other agents' minds in the group (even if this social value is not consensual) [15]. In short, individuals have beliefs about what defines the well-being of a society altogether and how public affairs should be governed in order to achieve a good social outcome (i.e. many individuals live well), and these may be incompatible with their individual values.

\subsubsection{Values in Policy-Making}

In broad terms, we understand policy-making as a process through which a group of agents, that we call policy-makers, design, enact, and evaluate a set of instruments to govern the activity of other agents, that we call policy-subjects, within some domain of activity [45]. A policy is devised in order to govern the activity of policy-subjects towards a state of the world that is deemed desirable by policy-makers as well as other relevant stakeholders [29]. Hence, governance is achieved through means like norms, incentives, and programmes, towards ends or intended outcomes of the policy. These policy ends are usually represented by some performance indicators or metrics that serve to assess whether the policy means are being successful [24].

According to Stewart [45], "policy design has a value-based component because the ways we attempt to change or influence behaviour depend on, in turn, beliefs about the reasons for that behaviour". In other words, the choice of policy means and ends reflects the mind-frames of policy-makers $[14,16,45]$. The adoption of a policy, on the other hand, depends on the decisions that policy-subjects make, thereby involving their mind-frames and, in particular, their values [13, 27, 29]. Thus, we assume that policy values are instantiated as means and ends according to their makers' mind-frames $[45,46]$.

\subsubsection{Reasoning with Values}

We adopt a consequentalist approach, that is, we reason about values through their effects: choose means because of the effects they achieve and ends through indicators that reflect those values (see [35]).

Moreover, we recognise that values may be prima facie incommensurable and thus lead to value conflicts [35]. Trade-offs may be based on the assumption of an ordering of values by relative importance invoking some form of "satisficing" combinations [44].

Finally, we assume that policy-makers reason on values by means of argumentation. Some works have approached practical reasoning in argumentation frameworks (for instance, $[3,48]$ ). Not to mention the role of values in design (as in policy-making and computational modelling $[5,30,35])$. 


\subsubsection{Simulation in Policy-Making}

Because of the complexity of policy-making, the use of simulation in policy design has been advocated to reproduce the dynamics of an artificial system so as to observe their behaviour and afterwards draw inferences and conclusions [21]. It enables to explore alternative policies without committing resources and disturbing the real social system, which produces useful evidence in order to identify successful and counterproductive pathways $[4,25]$.

Basically, an agent-based model (ABM) generates an "artificial society" from empirical knowledge that will be deployed for computational simulation [20, 22]. Ideally, these models capture the variety of decision-makers that interact within the system, which is particularly useful to model agents with distinct mind-frames as aforementioned.

Agent-based simulation has been used to study diverse policy domains: water resources management [8], land-use changes [33], agriculture [7, 40]; environmental programmes enrolment [43], and R\&D policy [1], among others.

\subsubsection{Water as a Policy Domain}

Water, as an essential resource, has an impact across the whole socio-economic and ecological system. Not surprisingly, water is at the heart of several social and ecological conflicts - which are aggravating due to the global change [12] and thus involves a rich repertoire of challenges in value-driven decision-making, argumentation, negotiation, collective agreement, and, in general, value-driven policy-making. Consequently, water management implies value-charged decisions, trade-offs, and ethical judgements of many sorts [9, 11, 16, 23, 32, 47, 50]. We believe that ABS is well fitted to address those challenges.

\subsection{An Outline of a Conceptual Framework}

We presume that values play a substantial role in policy-making. To this end, we propose to develop a conceptual framework to represent policy-making as a valuedriven social coordination process. The core of this proposal is outlined in Fig. 35.1.

In broad terms, we postulate that policy-making involves collective processes where policy-maker agents institute means and ends in order to influence the behaviour of policy-subjects so as to achieve a better state of a relevant part of the world. We say that these processes are value-driven because the choice and assessment of means and ends reflect the values of policy-makers, while the behaviour of policy-subjects responds to their private values. 
CONTEXT

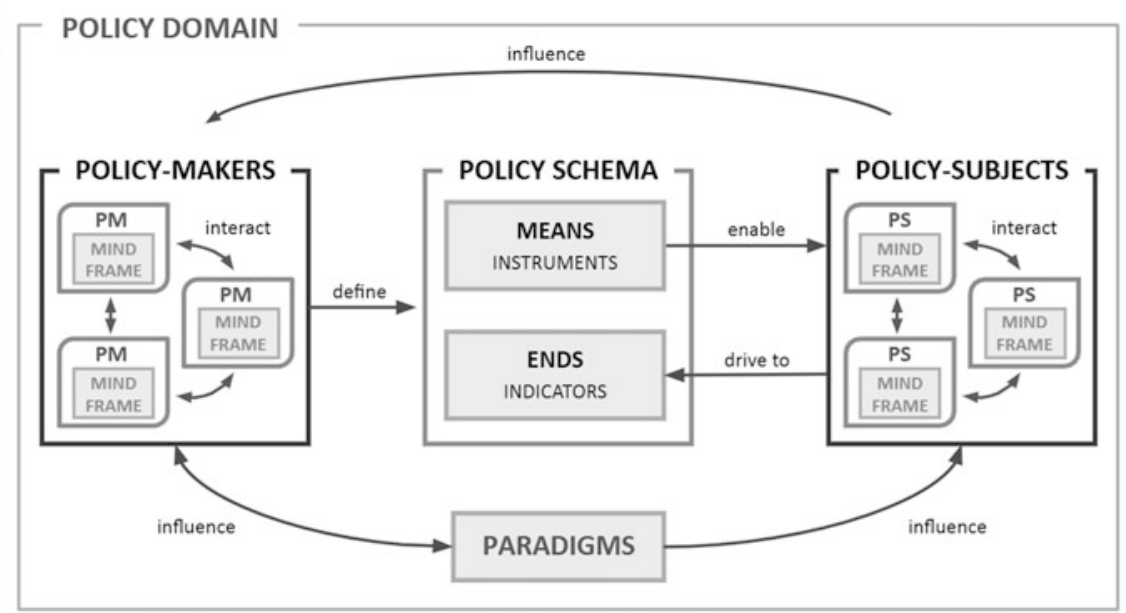

Fig. 35.1 Distinctive features of policy-making as a value-driven socio-cognitive system

We can be more precise:

1. Policy-making processes are a subclass of socio-cognitive technical systems (SCTS) [31]. Consequently, a policy-making process $\mathcal{P}$ has the following features:

s. $1 \mathcal{P}$ is situated in a physical/socio-economic context, and it organises and refers to activity and entities of a limited relevant fragment of that context: the policy domain.

s.2 Involves a class of stakeholders that contains at least two distinctive agent roles: policy-makers and policy subjects.

s.3 Agents behave according to their own mind-frames, which include personal values among other cognitive constructs.

s.4 A policy domain ontology that is the same for all stakeholders

s.5 An observable shared state of the world that is altered by events and actions.

s.6 Actions are conditioned by physical and normative constraints, but they may be further constrained by norms and conventions whose compliance and enforcement is determined and applied by stakeholders.

s.7 Agent interactions are organised in policy-making action arenas [36] ("scenes" [19]). We distinguish three arenas (that reflect the "policy-making cycle"):

(i) Policy definition: policy-maker factions negotiate their preferred policy means and policy ends and agree on their instrumentation (actions, norms, messages) and assessment (metrics, indicators).

(ii) Policy enactment: policy is proclaimed, policy-subjects perform afforded actions in the world of interest subject to the policy- 
related norms and alter the state of the world. Policy-subjects may act individually or collectively. Each agent has its own mind-frame that conditions its behaviour. In particular, individuals have their own values and metrics associated to their individual actions and the social outcome.

(iii) Policy evolution: policy-subjects may become aware of desirable changes in policy ends and means and negotiate among themselves and eventually with policy-makers.

\section{Policy-making processes are value-driven (see Sect. 35.2):}

v.1 Assumptions about values:

- We hold a consequentialist view of values. This entails that values are meant as their effects and thus may be projected by individuals or groups onto policy means (i.e. a norm $\phi$ or an action $\mu$ that promotes value $\alpha$ and demotes value $\beta$ ) and policy ends (i.e. world state $\sigma$ is better than state $\tau$ according to value $\alpha$ ).

- We distinguish between private values that are held by individual agents and collective agents and are involved in their decision-making and public values that are involved in the assessment of the "goodness" of actions, events, facts, governance means, and states of the world.

- For both types above, we distinguish between individual and social values. The first refer to individual agents, and the second are attributed to social groups.

- We do not require that values are commensurable and do not commit to the existence of forms of aggregating individual and social values.

v.2 Policy schema: is the explicit expression of the use of values in the way a policy will be instrumented and assessed. We distinguish two main constructs:

- Policy means are meant to foster activity of policy subjects towards the policy objectives. They essentially define, regulate, and motivate a set of institutionally affordable actions that are supported by instruments such as incentives, norms, and persuasion discourses.

- Policy ends define desirable future states intended to be achieved by the policy and are specified through a set of metrics and indicators to measure the evolving state of the social space.

v.3 Policy evaluation: policy-makers will draw on the policy schema to assess the success of a policy; however, agents may formulate additional ends and metrics (possibly kept private) and using the schema metrics and their own obtain a different assessment of the outcomes.

\section{Paradigms and mind-frames:}

p.1 Paradigms $[13,32]$ consist of social values, norms, and practices, as well as a shared ontology that recognises facts and actions and allows for intelligible representations of the world. A paradigm is somehow assumed 
by society and its members and is thus reflected in individual mind-frames and collective worldviews.

p.2 Paradigms are instantiated as policy paradigms that constitute legitimised worldviews adopted by policy-makers and policy-subjects. They prescribe means and ends seen as suitable for specific issues, as well as proscribe others.

p.3 In the policy definition and evolution arenas, policy-maker factions and organised policy subjects strive to steer public policies according to their mind-frames. Factions may try to redefine paradigms.

\section{Uses of the framework:}

u.1 To model a policy-making process in a given domain (we refer to this as the real-world model). Roughly, it serves for structuring the elements of the SCTS: policy-maker factions, policy-subjects with their values and frames, policy domain governance infrastructure, and policy schemata. It may have descriptive (understand the policy domain) or prescriptive roles (support the implementation of a policy schema).

u.2 A specification for an agent-based simulation that may be used to understand a policy domain, to explore potential interventions, and to argue about policy schemata. Although all arenas may be part of the implementation, the policy enactment arena is the one where ABS has proven most useful. Figure 35.2 depicts the core elements of the conceptual framework involved in the simulation of enactments.

u.3 The implementation of the model may provide the grounds for a policysupport systems that may be used in the different stages of the policy cycle. Note that once the policy is active, the implemented model may still work for monitoring actual outcomes.

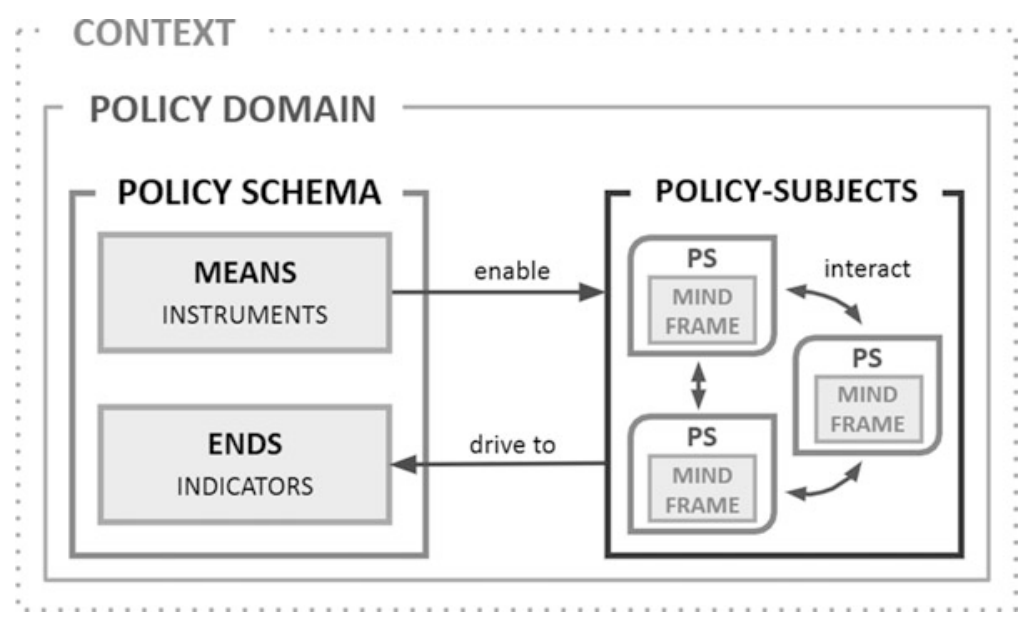

Fig. 35.2 Simulation components in the policy-enactment arena 


\subsection{An Illustrative Exercise}

We model a crude agriculture environment and simulate the enactment of two simplistic policies with policy subjects that conform to different value profiles. The point of the exercise is to exemplify the notions of policy schema, means, and ends and to illustrate the interplay of policy-maker and subject agent values.

Model The model represents a community of farmers who draw water from a watercourse, use it to irrigate a crop, and sell their production for profit. Rain provides both farmers and the watercourse with resources. The purpose of the model is to test policies (introduced as norms and actions). That is, to observe their effects on the socio-economic environment and their acceptance by stakeholders.

Scales The model simulates three decades of activity through discrete time steps. Each month it rains, water flows, and farmers irrigate. Each year, farmers harvest and sell their production and evaluate their happiness.

The spatial scale of the model represents a watershed where farmers share a water source. The land is represented with square patches. Patches have coefficients that are used to calculate the water runoff and the percolation. Precipitation and evapotranspiration are constant, uniform across the watershed, and distributed over the year by months (e.g. in summer, it rains less and evapotranspiration is higher). We model the watershed as two inclined rectangular planes that discharge into a water channel in the middle. The whole watershed discharges into a point where a flowmeter is placed.

Policy-makers We have two factions. One supports policy $P_{1}$; the other supports $P_{2}$ (see below). Both factions agree that irrigation agriculture is desirable for the public interest-which is the shared paradigm.

Policy-subjects Farmers are characterised by the following attributes: (i) mindframe; (ii) farm size; (iii) money; and (iv) crop water requirement. Also, farmers are able to (a) grow crops; (b) expand their farm; and (c) leave the farm. With regard to action (a) farmers demand water to complement the water required by the crop they grow-calculated as the reference evapotranspiration multiplied by a crop coefficient [2] - that is not supplied by the soil of their location.

Farmers' mind-frame can be either environmentalist or productivist. Farmers that subscribe to productivist values focus on their income and the satisfaction of their irrigation demands. In contrast, environmentalist farmers focus on the environment (i.e. on the volume of water in the watercourse) and, to a lesser extent, on their income. We assume that policy-subjects have private metrics.

Mind-frames (and values) determine the farmers' happiness, which is modelled as a dichotomous state. Happy farmers irrigate complying with applicable water constraints. However, unhappy farmers adjust their behaviour in order to improve their chances to be happy: productivist farmers ignore water constraints according to a probability, as long as they have less than a minimum amount of money; moreover, when they have enough money, they invest to increase their farm size, insofar as it is 
allowed. In contrast, environmentalist farmers always comply with constraints, and when they have enough money, their water withdrawal is only half of their actual demand.

Policy schema Policies include as means the action that farmers can irrigate their crops and sell their production for their own profit.

Policy $P_{1}$ embraces values like productivity and wealth. It focuses on the rural development of the basin, understood as the growth of farm industries and the wealth they generate $(e n d)$. It considers that promoted values may be measured as the average economic resources of farmers (metrics) — although there are other options, for instance, the total farming area of the basin. In parallel, the policy posits that the desired state is achieved when farmers can irrigate with low restrictions and they are able to expand their farms at will (means).

Policy $P_{2}$ holds environmentalist values like conservationalism and fairness. It aims at keeping the watershed in good environmental conditions (end). It establishes that the flow of the watercourse should be regularly monitored (metrics), and they support this statement with scientific studies that define an environmental threshold. Consequently, farmers can irrigate, but they cannot expand their farms (means). Also, they cannot extract more than a certain amount of resources. Additionally, their turn for irrigation will be determined according to their money amount, and not by their location, as it was by default (instruments).

\subsubsection{Simulations}

Experiment 1 focuses on the comparison between policy (factional) values.

Both policies are tested on an environment inhabited by a mixed population of policy-subjects. Let us assume that the value profile of the population is $50 \%$ productivist and 50\% environmentalist. Policy values of $P_{1}$ and $P_{2}$ are input into the simulation model as shown in Table 35.1 (three instruments and one metric for each policy).

The evolution of the simulated effects of both policies, according to the established metrics, are plotted in Figs. 35.3 and 35.4. As expected, the watercourse flow under $P_{1}$ has more acute seasonal variation, falling under the environmental

Table 35.1 Comparison between policy values (as input for the simulation)

\begin{tabular}{l|l|l}
\hline Input & $P_{1}$ & $P_{2}$ \\
\hline Water constraint ${ }^{\mathrm{a}}\left(\mathrm{m}^{3} /\right.$ ha/year $)$ & 10,000 & 1,000 \\
\hline Farm expansion & Enabled & Disabled \\
\hline Turn system (based on) & Distance & Money \\
\hline Main metrics & Money (per capita) & Flow $\left(\mathrm{m}^{3} /\right.$ month) \\
\hline
\end{tabular}

${ }^{\mathrm{a}}$ Distributed equally per month 
Fig. 35.3 Monthly flow evolution under both policies

Fig. 35.4 Money (average and standard deviation bands) evolution under both policies

Fig. 35.5 Minimum monthly flow of the year according to the water constraint
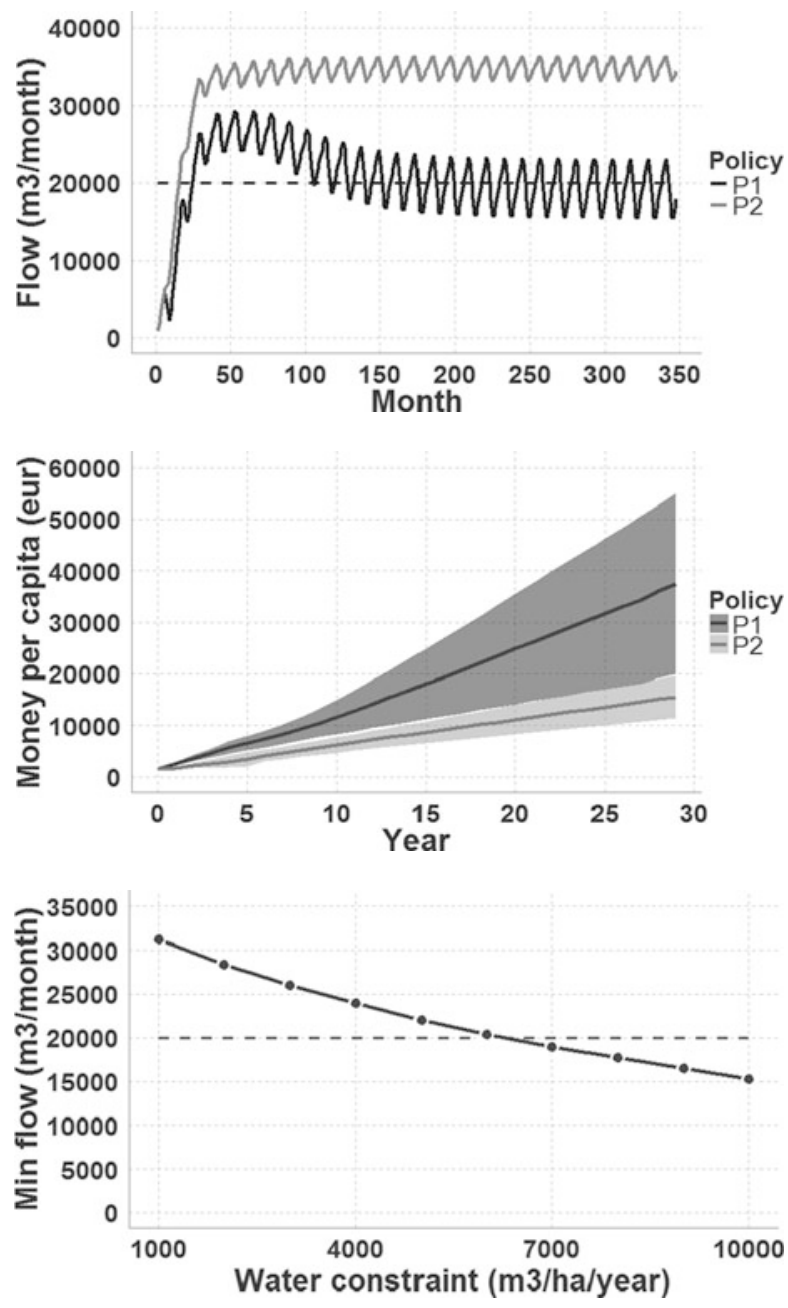

recommendation repeatedly. In contrast, the average of the money of farmers rises faster under $P_{1}$, although the deviation is lower under $P_{2}$.

These simulation results would be used to negotiate instruments in order to reach an end that satisfies both factions in a policy definition arena. For example, one may assume that both factions reach an agreement with regard to the other means, and therefore the negotiated policy (i) must enable the expansion of farms and (ii) must base the irrigation turns on farmer's worth. They focus on the long-term effects (in this case, after 30 years) to negotiate water constraints (Figs. 35.5 and 35.6). Observing the effects of policies, policy-makers could negotiate for a suitable water constraint, which would lead to the emergence of a consensual social value, as defined in Sect. 35.2. 
Fig. 35.6 Money (average) according to the water constraint

Fig. 35.7 Happiness (\%) with respect to mind-frames mix, under policy $P_{1}$
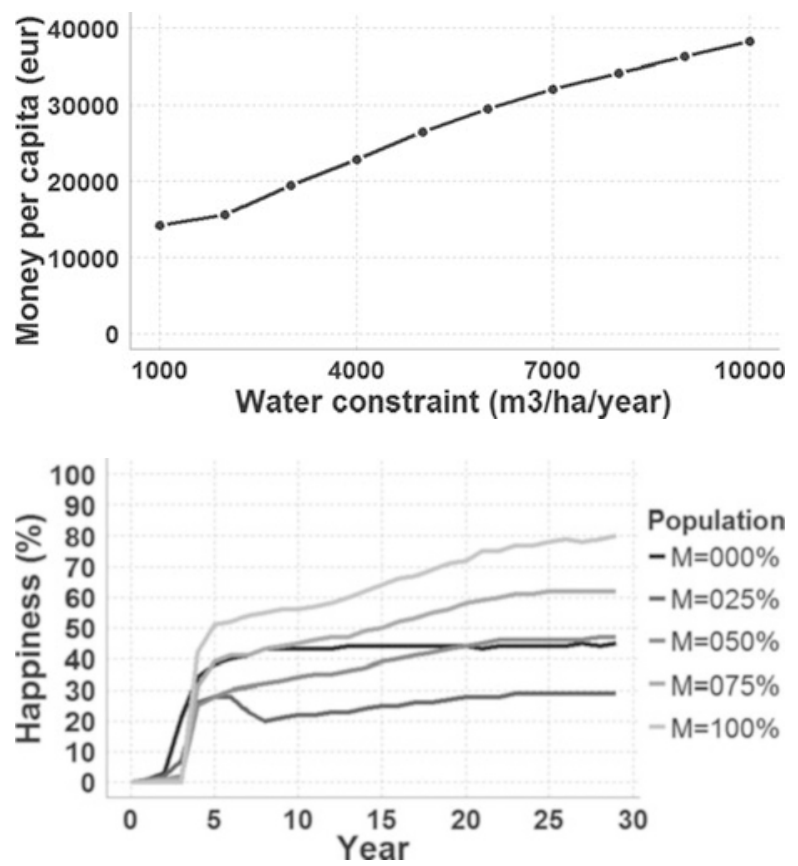

Experiment 2 contrasts the values of policy-makers and those of policy-subjects. That is, given a policy, how policy-subjects' support varies when altering their value profiles.

In this case, we do not care about the effects on the world, but rather the acceptance of policy-subjects, measured as the percentage of happy farmers. With $P_{1}$ as input (Table 35.1), we change the population of productivist $(M)$ and environmentalist $(E=100-M)$ farmers to observe the outcome.

Not surprisingly, the more productivist the farmers are, the happier (Fig. 35.7), since the policy values of $P_{1}$ match productivist values. However, the point of these experiments is to gauge acceptance in populations with mixed mind-frames. Curiously, when the population is completely environmentalist $(M=0 \%)$, the amount of happy farmers is nearly $50 \%$. The reason is that farmers do not disturb the ecosystem in spite of having a low water restriction-remember that they irrigate only a fraction as long as they have a certain amount of money. However, whenever there are productivist farmers $(M>0 \%)$, they use more resources-and even more when they increase their farms-driving environmentalist farmers unhappy.

We also compare farmers' acceptance (happiness) with water constraints for various population profiles (Fig. 35.8). Predictably, opposite population profiles have curves with slopes of opposite sign. When the population subscribes completely to environmentalist values, the constraint that leads to full happiness is the one promoted by $P_{2}$. On the contrary, a productivist population is happier with the lower constraints of $P_{1}$. Nevertheless, the latter does not achieve full happiness, because when all farmers increase their farms, the aggregate demand depletes the ecosystem. 
Fig. 35.8 Happiness (\%) according to the mind-frames and the water constraint

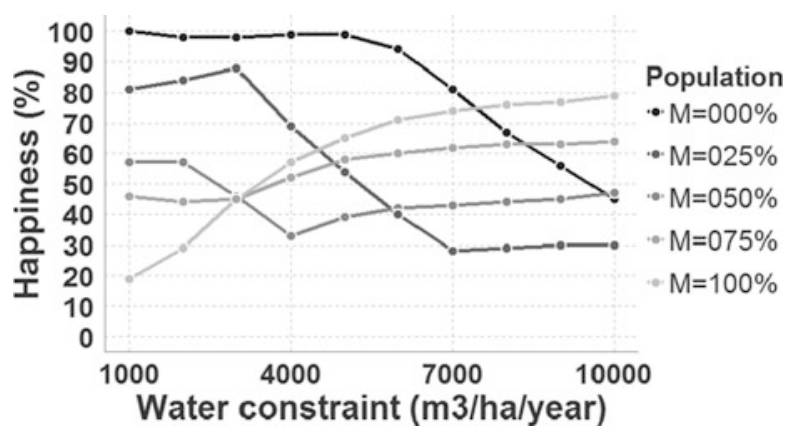

\subsection{Closing Remarks and Future Work}

We are interested in understanding the role that values play in the policy-making process and propose the use of agent-based simulation to support value-driven policy design. Our underlying assumption is that policy-makers can achieve a crisper understanding of the consequences of their proposals by making explicit the links between their values and the instruments and expected outcomes they choose. With that assumption in mind, we are convinced that the use of ABS to explore value-driven policy-making will provide a practical tool to support the complexand usually messy-policy cycle.

In this paper we intend to start substantiating those claims by addressing two specific objectives: first, to outline a conceptual framework that represents the policy-making process as a type of socio-cognitive system, specifically, a type where values are projected onto policy means (afforded actions and their governance mechanisms) and policy ends (metrics and performance indicators that evaluate the effect of agents behaviour on the state of the world). The second objective is to illustrate how agent-based simulation may be used within this framework to model a policy domain; in this case, water use.

Our intention is to further explore policy-making and values in the water policy domain, as it is a rich domain where all the essential components of policy-making are present and, with respect to our research focus, it involves multiple values and multiple stakeholders with different values and the possibility of exploring varied policy schemas [46]. We assume that the socio-hydrologic space can be modelled as a socio-cognitive technical system [31], and therefore the opportunities and challenges in the development of socio-cognitive agents are substantial and nontrivial $[15,31]$.

In order to further substantiate our claims, we identify the following lines of work:

Reasoning with values and about values: Value aggregation, value comparison, values and norms, values versus goals and preferences. 
Developing the notion of policy schema: What are the useful instruments to model? How can means and ends be represented in order to simulate reasoning about them? How are norms related with values?

Modelling the policy definition arena: Choosing a reference case. Use of valuebased argumentation. Negotiation as conflict resolution? A coherence-based analysis of faction values and actions.

Explore second-order phenomena: Policy adoption generally involves interplay between individual policy subjects and other stakeholders-political factions, special interest groups, and politicians - that react to emerging behaviour and may influence the social space, by sending rhetorical messages to influence other stakeholders, advocating policy changes, introducing incentives, and so on. These phenomena justify bringing some second-order affordances like macroperception, collective illocutions, and instrument revision into the meta-model.

Addressing empirical questions: Identify domain-specific values, instruments, and indicators. Validation of stakeholder profiles. Development of a "scoring methodology" and value-aggregation models. How to make a simulation model useful.

Explore the usability of the framework: The interplay between the number of afforded actions and values in dispute. Negotiation with ABS support.

Ethical aspects of the use of agent-based models for policy-making: We identify three basic types of issues: (i) Issues involved in the selection and implementation of values for the policy and for the agent's reasoning models (ii) Issues related to the construction of the model itself: assumptions, functionality, and range of application (iii) Issues associated with the use of the agent-based model along the policy cycle. Awareness of the policy-makers about the limitations and scope of system, commitments associated with the use of actual simulations, and so on. Awareness of other stakeholders of the use and validity of the model

We are aware that the design and assessment of public policies entail a multidisciplinary approach. We trust that our value-driven simulation approach will be attractive to professionals from different fields.

Acknowledgements The first author is supported with the industrial doctoral 2016DI043 grant of the Catalan Secretariat for Universities and Research (AGAUR), sponsored by FCC AQUALIA, IIIA-CSIC, and UAB. This work has been supported by the Catalan-funded AppPhil project (funded by RecerCaixa 2017) and the Spanish-funded CIMBVAL project (funded by the Spanish government, project \# TIN2017-89758-R).

\section{References}

1. Ahrweiler, P.: Agent-based simulation for science, technology, and innovation policy. Scientometrics 110(1), 391-415 (2017)

2. Allen, R.G., Pereira, L.S., Raes, D., Smith, M.: Crop evapotranspiration-guidelines for computing crop water requirements. United Nations. http://www.fao.org/3/X0490E/X0490E00. htm, FAO Paper 56 (1998) 
3. Atkinson, K., Bench-Capon, T.: Practical reasoning as presumptive argumentation using action based alternating transition systems. Artif. Intell. 171(10), 855-874 (2007). Argumentation in Artificial Intelligence

4. Banks, J.: Handbook of Simulation. Wiley, Inc., Upper Saddle River (1998)

5. Bannister, F., Connolly, R.: ICT, public values and transformative government: a framework and programme for research. Gov. Inf. Q. 31(1), 119-128 (2014)

6. Beratan, K.K.: A cognition-based view of decision processes in complex social-ecological systems. Ecol. Soc. 12(1), 27 (2007)

7. Berger, T.: Agent-based spatial models applied to agriculture: a simulation tool for technology diffusion, resource use changes and policy analysis. Agric. Econ. 25(2), 245-260 (2001)

8. Berglund, E.Z.: Using agent-based modeling for water resources planning and management. J. Water Resour. Plan. Manag. 141(11), 04015025 (2015)

9. Boelens, R., Hoogesteger, J., Swyngedouw, E., Vos, J., Wester, P.: Hydrosocial territories: a political ecology perspective. Water Int. 41(1), 1-14 (2016)

10. Bostrom, A., Fischhoff, B., Morgan, M.G.: Characterizing mental models of hazardous processes: a methodology and an application to radon. J. Soc. Issues 48(4), 85-100 (1992)

11. Brown, P., Schmidt, J.: Water Ethics: Foundational Readings for Students and Professionals. Island Press, Washington, DC (2010)

12. Camill, P.: Global change. Nat. Educ. Knowl. 3(10), 49 (2010)

13. Campbell, J.L.: Institutional analysis and the role of ideas in political economy. Theory Soc. 27(3), 377-409 (1998)

14. Campbell, J.L.: Ideas, politics, and public policy. Annu. Rev. Sociol. 28(1), 21-38 (2002)

15. Castelfranchi, C.: Minds as social institutions. Phenomenol. Cogn. Sci. 13(1), 121-143 (2014)

16. Castro, J.E.: Water governance in the twentieth-first century. Ambiente Sociedade 10(2), 97$118(2007)$

17. DeCaro, D.A., Arnold, C.A.T., Frimpong Boamah, E., Garmestani, A.S.: Understanding and applying principles of social cognition and decision making in adaptive environmental governance. Ecol. Soc. 22(1), 33 (2017)

18. Dietz, T., Fitzgerald, A., Shwom, R.: Environmental values. Annu. Rev. Environ. Resour. 30(1), 335-372 (2005)

19. d'Inverno, M., Luck, M., Noriega, P., Rodriguez-Aguilar, J.A., Sierra, C.: Communicating open systems. Artif. Intell. 186, 38-94 (2012)

20. Galán, J.M., Izquierdo, L.R., Izquierdo, S.S., Santos, J.I., del Olmo, R., López-Paredes, A., Edmonds, B.: Errors and artefacts in agent-based modelling. J. Artif. Soc. Soc. Simul. 12(1), 1 (2009)

21. Gilbert, N., Ahrweiler, P., Barbrook-Johnson, P., Narasimhan, K.P., Wilkinson, H.: Computational modelling of public policy: reflections on practice. J. Artif. Soc. Soc. Simul. 21(1), 14 (2018)

22. Gilbert, N., Conte, R., et al.: Artificial Societies: The Computer Simulation of Social Life. Routledge, London/New York (2006)

23. Groenfeldt, D., Schmidt, J.J.: Ethics and water governance. Ecol. Soc. 18(1), 14 (2013)

24. HM Treasury.: The Magenta Book: Guidance for Evaluation (2011)

25. Jager, W., Edmonds, B.: Policy making and modelling in a complex world. In: Janssen, M., Wimmer, M.A., Deljoo, A. (eds.) Policy Practice and Digital Science: Integrating Complex Systems. Social Simulation and Public Administration in Policy Research, pp. 57-73. Springer International Publishing, Cham (2015)

26. Jones, N.A., et al.: Mental Models: An Interdisciplinary Synthesis of Theory and Methods. Ecol. Soc. 16(1), 46 (2011)

27. Jones, N.A., et al.: The study of human values in understanding and managing social-ecological systems. Ecol. Soc. 21(1), 15-24 (2016)

28. Kenter, J.O., et al.: What are shared and social values of ecosystems? Ecol. Econ. 111(Supplement C), 86-99 (2015)

29. May, P.J.: Policy design and implementation. In: Peters, B., Pierre, J. (eds.) The SAGE Handbook of Public Administration, 2nd edn., pp. 279-291. SAGE Publications, Los Angeles (2012) 
30. Moody, R., Gerrits, L.: Introduction to policy-making in the digital age. In: Janssen, M., Wimmer, M.A., Deljoo, A. (eds.) Policy Practice and Digital Science: Integrating Complex Systems. Social Simulation and Public Administration in Policy Research, pp. 205-219. Springer International Publishing, Cham (2015)

31. Noriega, P., Padget, J., Verhagen, H., d'Inverno, M.: Towards a framework for socio-cognitive technical systems. In: Ghose, A., Oren, N., Telang, P., Thangarajah, J. (eds.) Coordination, Organizations, Institutions, and Norms in Agent Systems X. Lecture Notes in Computer Science, vol. 9372, pp. 164-181. Springer, Cham (2015)

32. Pahl-Wostl, C.: Water Governance in the Face of Global Change. Springer International Publishing, Cham (2015)

33. Parker, D.C., Manson, S.M., Janssen, M.A., Hoffmann, M.J., Deadman, P.: Multi-agent systems for the simulation of land-use and land-cover change: a review. Ann. Assoc. Am. Geogr. 93(2), 314-337 (2003)

34. Parks, L., Guay, R.P.: Personality, values, and motivation. Personal. Individ. Differ. 47(7), 675684 (2009)

35. van de Poel, I.: Translating values into design requirements. In: Michelfelder, D.P., McCarthy, N., Goldberg, D.E. (eds.) Philosophy and Engineering: Reflections on Practice, Principles and Process, pp. 253-266. Springer Netherlands, Dordrecht (2013)

36. Polski, M., Ostrom., E.: An institutional framework for policy analysis and design in workshop in political theory and policy analysis (1999), Working Paper No. W98-27

37. Rohan, M.J.: A rose by any name? The values construct. Personal. Soc. Psychol. Rev. 4(3), 255-277 (2000)

38. Rokeach, M.: The Nature of Human Values. Free Press, New York (1973)

39. Rokeach, M.: Understanding Human Values. Simon and Schuster, New York (2008)

40. Schreinemachers, P., Berger, T.: An agent-based simulation model of human-environment interactions in agricultural systems. Environ. Model. Softw. 26(7), 845-859 (2011)

41. Schwartz, S.H., Bilsky, W.: Toward a theory of the universal content and structure of values: extensions and cross-cultural replications. J. Pers. Soc. Psychol. 58(5), 878 (1990)

42. Searle, J.: Rationality in Action. MIT Press, Cambridge (2003)

43. Sengupta, R., Lant, C., Kraft, S., Beaulieu, J., Peterson, W., Loftus, T.: Modeling enrollment in the conservation reserve program by using agents within spatial decision support systems: an example from Southern Illinois. Environ. Plann. B. Plann. Des. 32(6), 821-834 (2005)

44. Simon, H.A.: Bounded rationality. In: Eatwell, J., Milgate, M., Newman, P. (eds.) Utility and Probability, pp. 15-18. Palgrave Macmillan, London (1990)

45. Stewart, J.: Value Conflict and Policy Change. Palgrave Macmillan, London (2009)

46. Veeneman, W., Dicke, W., Bruijne, M.: From clouds to hailstorms: a policy and administrative science perspective on safeguarding public values in networked infrastructures. Int. J. Public Policy 4, 414-434 (2009)

47. Vugteveen, P., Lenders, H.J.R., Devilee, J.L.A., Leuven, R.S.E.W., van der Veeren, R.J.H.M., Wiering, M.A., Hendriks, A.J.: Stakeholder value orientations in water management. Soc. Nat. Resour. 23(9), 805-821 (2010)

48. van der Weide, T.L., Dignum, F., Meyer, J.C., Prakken, H., Vreeswijk, G.A.W.: Practical reasoning using values: giving meaning to values. In: Proceedings of the 6th International Conference on Argumentation in Multi-Agent Systems, ArgMAS'09, pp. 79-93. Springer, Berlin/Heidelberg (2010)

49. Witesman, E.M., Walters, L.C.: Modeling public decision preferences using context-specific value hierarchies. Am. Rev. Public Adm. 45(1), 86-105 (2015)

50. Zeitoun, M., Warner, J.: Hydro-hegemony - a framework for analysis of trans-boundary water conflicts. Water Policy 8(5), 435-460 (2006) 